\title{
Structural characterization, immune regulation and antioxidant activity of a new heteropolysaccharide from Cantharellus cibarius Fr.
}

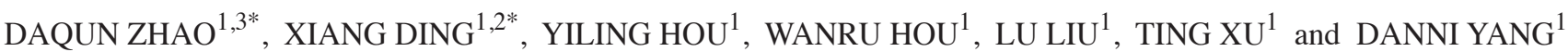 \\ ${ }^{1}$ Key Laboratory of Southwest China Wildlife Resources Conservation (Ministry of Education), College of Life Sciences, \\ ${ }^{2}$ College of Environmental Science and Engineering, China West Normal University, Nanchong, Sichuan 637009; \\ ${ }^{3}$ School of Basic Medical Sciences, Southwest Medical University, Luzhou, Sichuan 646699, P.R. China
}

Received October 6, 2016; Accepted January 26, 2018

DOI: $10.3892 / \mathrm{ijmm} .2018 .3450$

\begin{abstract}
A new heteropolysaccharide was extracted and purified from the fruiting bodies of Cantharellus cibarius Fr. The Cantharellus cibarius Fr. polysaccharide (CC-1) had a molecular weight of $61,056 \mathrm{kDa}$ and was mainly formed of the glucose and xylose at ratio of 5:1. Structure identification of CC-1 was analysed by a combined application of total hydrolysis, high performance liquid chromatography (HPLC), methylation analysis, gas chromatography-mass spectrometry (GC-MS), infrared (IR) spectra and nuclear magnetic resonance (NMR) spectroscopy. The experimental results showed that $\mathrm{CC}-1$ had a backbone of 1,4-linked- $\beta$-D-glucose which branched at O-6 and the branches were mainly composed of $6 \rightarrow 1$ )- $\alpha$-D-xylopyranose residue. CC-1 exhibited significant in vitro antioxidant effect and proliferation effect of immune cells. The activity study showed $\mathrm{CC}-1$ has ability to clear the $\mathrm{ABTS}^{+}$free radical and $\mathrm{DPPH}^{-}$free radical in a certain range of concentration. The proliferation activity of the immune cells showed that the proliferation effect on $\mathrm{B}$ cells was very significant $(\mathrm{P}<0.001)$ in the concentration of $0.625-80 \mathrm{mg} / \mathrm{ml}$; and the effect of $\mathrm{T}$ cell proliferation was also very significant $(\mathrm{P}<0.001)$ in the concentration of $5-20 \mathrm{mg} / \mathrm{ml}$. The result of this study introduced Cantharellus cibarius Fr. as a possible valuable source in exhibiting unique immunoregulatory and antioxidant properties.
\end{abstract}

\section{Introduction}

Fungus is a member of eukaryotic organisms, also including multicellular fungi, for example, all kinds of mushrooms (1). Fungi

Correspondence to: Professor Yiling Hou, Key Laboratory of Southwest China Wildlife Resources Conservation (Ministry of Education), College of Life Sciences, 1 Shida Road, Nanchong, Sichuan 637009, P.R. China

E-mail: starthlh@126.com

"Co-first authors

Key words: polysaccharide, structure, antioxidant effect, proliferation effect, immune cells is separate from the animals, plants, protists and bacteria (2). The human use of fungi for food preparation has a long history. Mushroom farming and mushroom gathering are large industries in many countries $(3,4)$. The ethnomycology is the study of sociological impact and historical uses of fungi $(5,6)$. Because of the capacity of this group to produce an enormous range of natural products with antibacterial and other biological activities, many species have long been used or are being developed for industrial production of antibiotics, vitamins, and anticancer and anticholesterol drugs (7-9). Many species produce metabolites that are major sources of pharmacological drugs (10). Particularly important are the antibiotics, including penicillins, a structurally related group of $\beta$-lactam antibiotics that are synthesized from small peptides.

Polysaccharides are long sugar chains which are combined with the glucosidic bond, and they are polymeric carbohydrate molecules consisting of more than 10 mono-saccharide units $(11,12)$. Cell-surface polysaccharides play a great role in the procedure of metabolism (13). They are one of the four basic substances of life (14). Polysaccharide is a composite of nucleotide-activated precursor $(15,16)$. Lipopolysaccharide is the most imperative of cell-surface polysaccharides. It has an impossibly key effect on cell membrane structures, and is momentous material of the cell-membrane receptor.

Cantharellus cibarius Fr. is a fungi which grows in Aba country of Sichuan province in China at an elevation of 3,600 m. In this study, the polysaccharide was got from the fruiting bodies of Cantharellus cibarius Fr. by using DEAE-cellulose column. Its chemical structures were characterized for the first time. The structural analysis of the fraction was done by using chemical methods, high performance liquid chromatography (HPLC), infrared (IR) spectroscopy, and nuclear magnetic resonance (NMR) spectroscopy. The antioxidant activity and proliferation impact of immune cells of CC-1 was evaluated in vitro. The result of this study introduced Cantharellus cibarius Fr. as a possible valuable source which is helpful to exhibit unique antioxidant and immune regulation properties.

\section{Materials and methods}

Chemicals. Cantharellus cibarius Fr. were collected in Xiaojing Country of Sichuan province, China, and were authenticated by 
Professor Xiang Ding (College of Life Sciences, China West Normal University, Nanchong, China). A voucher specimen has been deposited in Key Laboratory for Biological Resource and Ecological Environment of Education Ministry, College of Life Sciences, Sichuan University. Monosaccharides were from Beijing Biodee Biotechnology Co., Ltd. (Beijing, China). DEAECellulose-52 was from Sigma-Aldrich (Mainland, China). The other reagents used were of analytical grade. The other reagent 2-(2-methoxy-4-nitrophenyl-)-3-(4-nitrophenyl)-5-(2,4-disulfonic acid benzene)-2H-tetrazolium monosodium salt (CCK-8) was purchased from Dojindo Molecular Technologies, Inc. (Tokyo, Japan); D-Hanks solution, RPMI-1640 medium, fetal calf serum, and dimethyl sulfoxide were purchased from Gibco (Grand Island, NY, USA). Penicillin G and streptomycin were from Sigma-Aldrich $(17,18)$.

Extraction of polysaccharides from Cantharellus cibarius Fr. Cantharellus cibarius Fr. fruiting bodies (400 g), soaked with $95 \%$ EtOH (6 h) to remove lipids by filtration (19-22). The residue was dried and extracted with boiling water three times (6 h each). Refined polysaccharides were obtained by concentrated filtrate, dialysis (MWCO 7000; Sigma) centrifugation to remove impurity substance and small molecule compounds. Adding 95\% EtOH at 3 times volume in the supernatant liquid precipitation crude polysaccharides, then drying in vacuo at $45^{\circ} \mathrm{C}$, yielding the crude Cantharellus cibarius Fr. polysaccharide (CC-1) (12.7 g, recovery $3.175 \%)$. DEAE-Sepharose fast flow column was used to extract and purify polysaccharides of Cantharellus cibarius Fr. polysaccharide, named CC-1.

Molecular weight determination of polysaccharide CC-1. Molecular weight of polysaccharides were obtained by high-performance gel permeation chromatography (HPGPC) (23). Deionized water was used to make dextran standards and CC-1 dissolve at a concentration of $2.0 \mathrm{mg} / \mathrm{ml}$ and then analyzed on an Agilent 1100 series HPLC system to determine the retention time of standards and samples (24). The column and detector compartment were maintained at 30 and $35^{\circ} \mathrm{C}$, respectively. Distilled water was used in mobile phase, and detection rate was $1.0 \mathrm{ml} / \mathrm{min}$ and tested volume was $10 \mu \mathrm{l}$. The molecular weight of CEC-A was calculated by constructing a calibration curve, in which the logarithm of the molecular weight of the Dextran standards ranged from $10,000-500,000 \mathrm{kDa}$ as standard of the retention time using Agilent ChemStation GPC Data Analysis Software (Millennium 32 software) (18).

Fourier transform infrared spectrometer (FT-IR) analysis. Infrared spectroscopy is based on the fact that when molecules absorb energy, undergo a transition to a state of higher energy or excited state, and only vibrational energy transitions occur in the mid-infrared region. The vibrations induced by infrared radiation include strains and tensions of interatomic bonds and changes of bonds angles. Thus, the vibration frequency can be associated with a particular bond type (25). In this study, FT-IR spectra of CC-1 was measured by grinding a mixture of polysaccharide with dry $\mathrm{KBr}$ and then pressing in a mold. Spectra was collected using a Thermo Nicolet 6700 FT-IR Spectrophotometer (Thermo
Fisher Scientific, Grand Island, NY, USA) in the coverage of $400-4000 \mathrm{~cm}^{-1}$ at resolution ratio of $4 \mathrm{~cm}^{-1}(26)$.

NMR experiment. The polysaccharide was dissolved in deuteroxide accompanied with ultraonic wave precessing for $20 \mathrm{~min}$. The Varian Unity INOVA 400/45 (Varian Technologies, Palo Alto, CA, USA) was used to perform the ${ }^{1} \mathrm{H}$ NMR spectra and ${ }^{13} \mathrm{C}$ NMR spectra analysis with tetramethylsilane as internal standard (27).

Monosaccharide composition analysis of CC-1. CC-1 $(10 \mathrm{mg}$ ) was hydrolyzed in $2 \mathrm{~mol} / 1$ trifluoroacetic acid at $100^{\circ} \mathrm{C}$ for $6 \mathrm{~h}$ on the mechanism of acid-catalyzed hydrolysis (18). The residual acid was removed with methyl alcohol $(\mathrm{MeOH})$ and taking to dryness three times. After the hydrolysis was completed, samples were dissolved with distilled water for analyzing monosaccharide composition. The hydrolyzates of CC-1 were analyzed by HPLC on an Agilent 1100 series HPLC (Agilent Technologies, Palo Alto, CA, USA) equipped with a RID (28). The injection volume of mixed monosaccharide standards and $\mathrm{CC}-1$ hydrolyzates was $10 \mu \mathrm{l}$. The temperature of the column was set at $35^{\circ} \mathrm{C}$. $\mathrm{D}$-glucose, D-xylose, D-fructose, D-galactose, L-arabinose and D-mannose were used as standard sugars.

Methylation analysis and gas chromatography-mass spectrometry (GC-MS). According to literature, we can use methyl iodide to make polysaccharide methylation (29). Then the permethylated product was depolymerized with $90 \%$ formic acid at $100^{\circ} \mathrm{C}$ for $4 \mathrm{~h}$ and further hydrolysed with $2 \mathrm{M}$ TFA at $100^{\circ} \mathrm{C}$ for $6 \mathrm{~h}$. The resulting products were derivatized using reagent and analyzed using Agilent Technologies 7890A GC-MS system (Agilent Technologies) (29).

$D P P H^{-}$radical scavenging activity. The $\mathrm{DPPH}^{-}$radical scavenging activity of the polysaccharide sample was measured by a decrease in absorbance at $517 \mathrm{~nm}$ of a solution of purplecoloured $\mathrm{DPPH}^{-}$in methanol brought about by the sample (30). The degree of free radical scavenging rate can be judged by the size of the absorbance. The higher the absorbance, the weaker the free radical scavenging ability. Absorbance at $517 \mathrm{~nm}$ is measured after $30 \mathrm{~min}$ using UV-Visible Spectrometer. According to the formula to calculate the free radical scavenging rate of DPPH:

$$
\text { DPPH scavenge }(\%)=\left[\frac{1-A_{\text {test }}}{A_{\text {control }}}\right] \times 100 \%
$$

A control represents the blank control group, A test represents the absorbance in the presence of the polysaccharide sample. In the study, the antioxidant activity of the extract was compassed with vitamin $\mathrm{C}(\mathrm{Vc})$.

ABTS radical scavenging activity. $\mathrm{ABTS}^{+}$radical scavenging activity of the polysaccharide extracts and fractions was measured by the $\mathrm{ABTS}^{+}$cation decolorization assay (31). The $\mathrm{ABTS}^{+}$radical cation was confected by reaction of $7 \mathrm{mM}$ stock solution of $\mathrm{ABTS}^{+}$with $2.45 \mathrm{mM}$ ammonium persulphate (APS) and then admixture at room temperature in the dark for $16 \mathrm{~h}$. Then $2 \mathrm{ml}$ of various concentrations of the sample and $2 \mathrm{ml}$ of $\mathrm{ABTS}^{+}$radical solution $(0.7 \mathrm{mM})$ were 


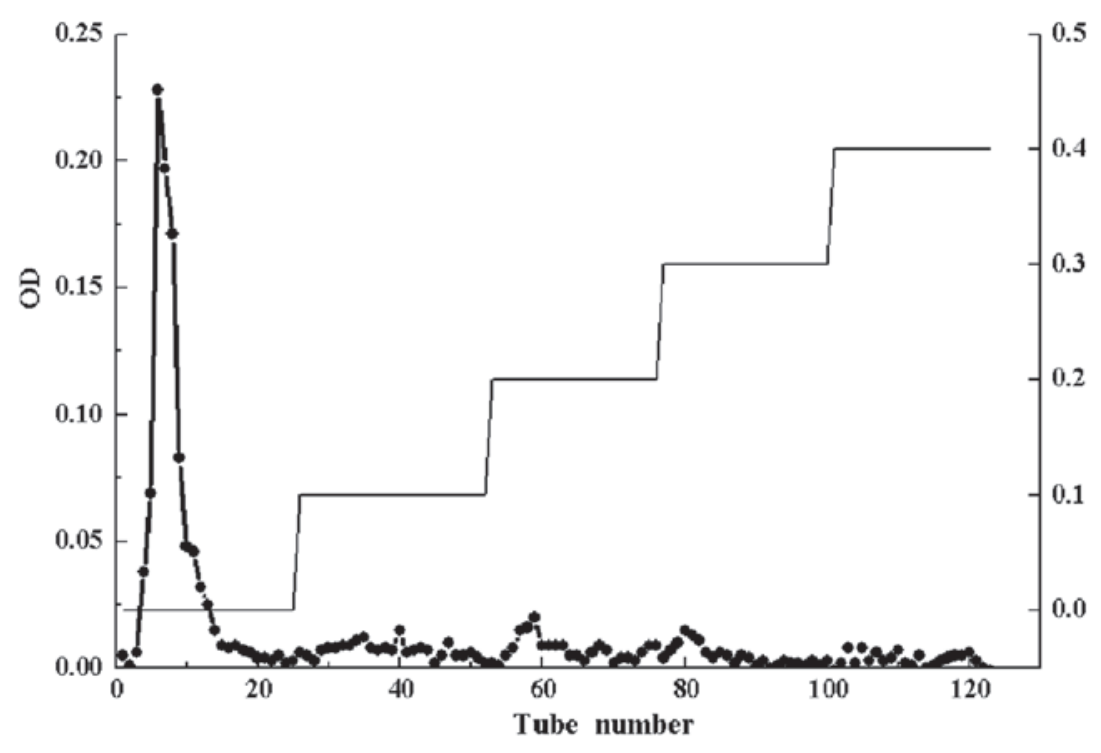

Figure 1. DEAE cellulose-52 column chromatography elution curve of Cantharellus cibarius Fr. polysaccharide (CC-1). The horizontal coordinate represents the tube number of chromatography separation, and the longitudinal coordinate indicates the OD value.

added. A control reaction was carried out without the polysaccharide extracts. The absorbance was measured immediately at $734 \mathrm{~nm}$. The percentage of scavenging of hydrogen radicals was calculated as follows:

Scavenging effect $(\%)=\left[1-\frac{\left(A_{\text {sample }}-A_{\text {sample }+ \text { blank }}\right)}{A_{\text {control }}}\right] \times 100 \%$

where A control represents the absorbance of the control group in the $\mathrm{ABTS}^{+}$radicals generation system, A sample was the absorbance of the test group and A sample blank was the absorbance of the samples only. Vc was used as a positive control in the study.

Cell lines and reagents. The $\mathrm{T}$ cell line and $\mathrm{B}$ cell line (Raji) were cultured in RPMI-1640 medium containing 10\% fetal bovine serum (FBS), $1 \%$ penicillin $(100 \mathrm{IU} / \mathrm{ml})$ and streptomycin $(100 \mathrm{mg} / \mathrm{l})$ in a humidified atmosphere with $5 \% \mathrm{CO}_{2}$ at $37^{\circ} \mathrm{C}$ before use.

Pharmacological evaluation for $B$ cells and $T$ cells stimulation. The cytotoxic effects of $\mathrm{CC}-1$ on $\mathrm{B}$ cells and $\mathrm{T}$ cells were determined by CCK-8-based colorimetric method (32). Briefly, B cells and T cells suspended in RPMI-1640 medium at a density of $1 \times 10^{5}$ cells $/ \mathrm{ml}$ were pipetted into a 96 -well plate (100 $\mu \mathrm{l} /$ well) and inoculated at $37^{\circ} \mathrm{C}$ in a humidified $5 \% \mathrm{CO}_{2}$. After incubation for $24 \mathrm{~h}, 100 \mu \mathrm{l}$ of test sample with different concentrations $(0.625-80 \mu \mathrm{g} / \mathrm{ml}$ in fresh growth medium) was added into each well, respectively, in an incubator at $37^{\circ} \mathrm{C}$ in a humidified $5 \% \mathrm{CO}_{2}$ for $48 \mathrm{~h}$. RPMI-1640 and $5 \mu \mathrm{g} / \mathrm{ml}$ lipopolysaccharide (LPS) was used as negative and positive controls, respectively. Then, $10 \mu \mathrm{l}$ of CCK- 8 reagent was added to each well, then the cells were cultured in the incubator for $3 \mathrm{~h}$. Absorbance of the cells in 96-well microplate was evaluated by ELISA (Bio-Rad, Tokyo, Japan) at $490 \mathrm{~nm}$.

Cell morphology observation. The morphology of T cell line and B cell line (Raji) was observed under an inverted microscope (Olympus IX71; Olympus, Tokyo, Japan).
Statistical methods. The data in this study were analyzed as the standard deviation (SD) of three replications. Data processing was by One way analysis of variance and Student's t-test. $\mathrm{P}<0.05$ represents a significant difference between the data.

\section{Results}

Determination of molecular weight. Molecular weight of CC-1 was evaluated by HPLC-GPC. HPGPC of the polysaccharide fraction shows that each fraction was represented by a broad and symmetrical peak on the chromatograms. Fig. 1 shows DEAE cellulose-52 column chromatography and high performance gel permeation chromatogram of $\mathrm{CC}-1$, respectively. The molecular weight (Mw) of CC-1 was $61,056 \mathrm{kDa}$, the peak molecular weight was 7,160 kDa, the average molecular weight was $3,136 \mathrm{kDa}$, and the polydispersity was 19.47 (Fig. 2). The polydispersity indicates the polymer molecular weight distribution. The greater the polydispersity is the wider the molecular weight distribution. Generally, the range of polydispersity value of the polymer is 1.5-2.0, sometimes as high as 20-50. The polydispersity of CC-1 was 19.47 , which indicated a good molecular weight distribution.

Fourier transform infrared spectrometer (FT-IR) analysis. FT-IR was used for structure analysis of CC-1 (Fig. 3). The bands at $3428.70 \mathrm{~cm}^{-1}$ were detection results of $\mathrm{OH}$ bond stretching. The absorption peak at $2924.26 \mathrm{~cm}^{-1}$ was $\mathrm{C}-\mathrm{H}$ stretching of vibration absorption peak of $\mathrm{CC}-1$. The strong absorption band at $1643.12 \mathrm{~cm}^{-1}$ was caused by $\mathrm{OH}$ deformation vibration. The bands at $1404.39 \mathrm{~cm}^{-1}$ arose from bending modes of $\mathrm{CH}_{2}, \mathrm{CH}$ and $\mathrm{OH}$.

The absorption peaks at $1041.07 \mathrm{~cm}^{-1}$ in the range of $1200-1000 \mathrm{~cm}^{-1}$ in the IR spectrum suggested that the monosaccharides in the samples had a pyranose-ring. Partially, the bands at $1041.07 \mathrm{~cm}^{-1}$ were associated with the ordered and amorphous structures in CC-1. The bands in the region 


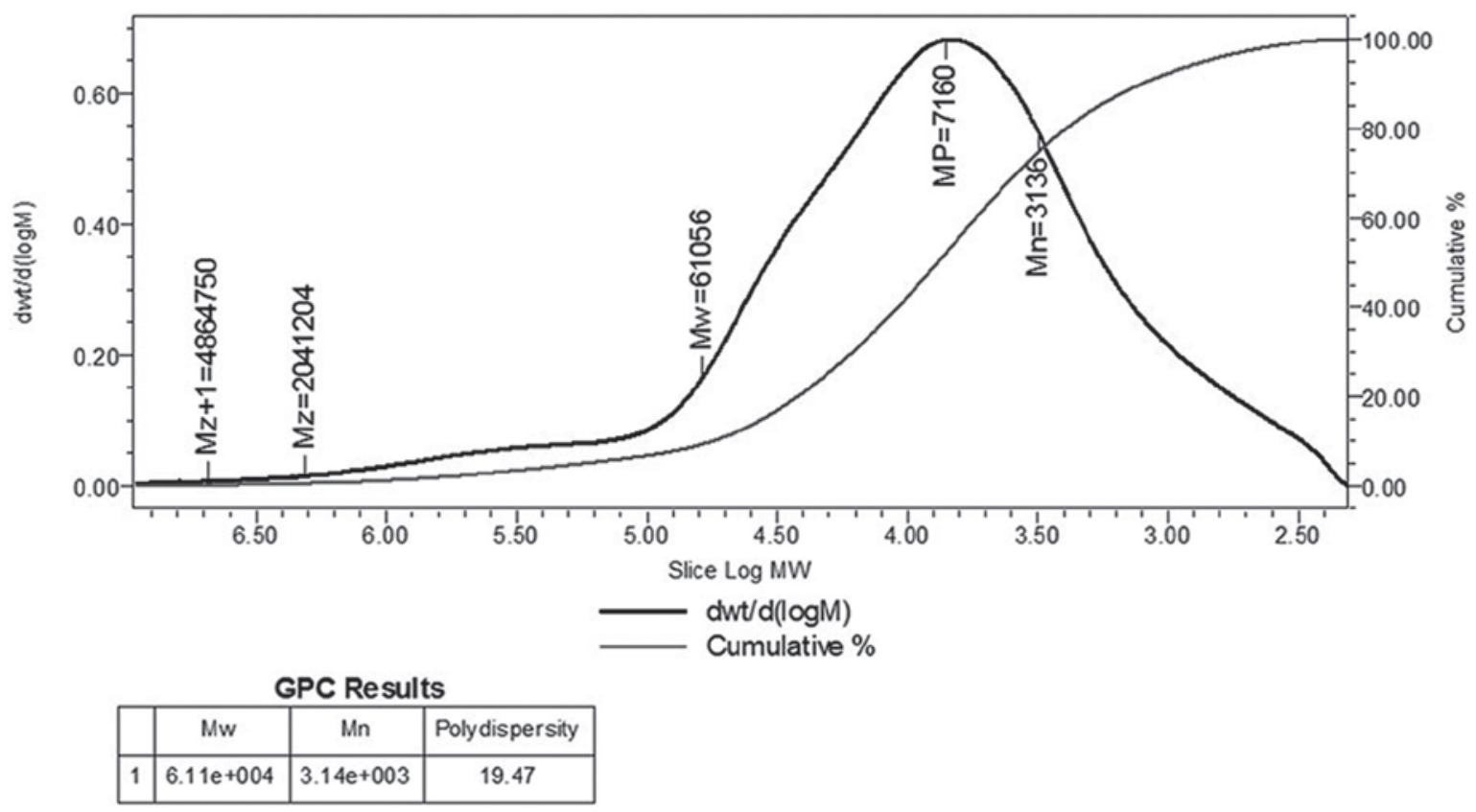

Figure 2. Molecular weight determination spectrum of Cantharellus cibarius Fr. polysaccharide (CC-1) by HPGPC. The curve is the molecular weight distribution curve of computer automatic statistics.

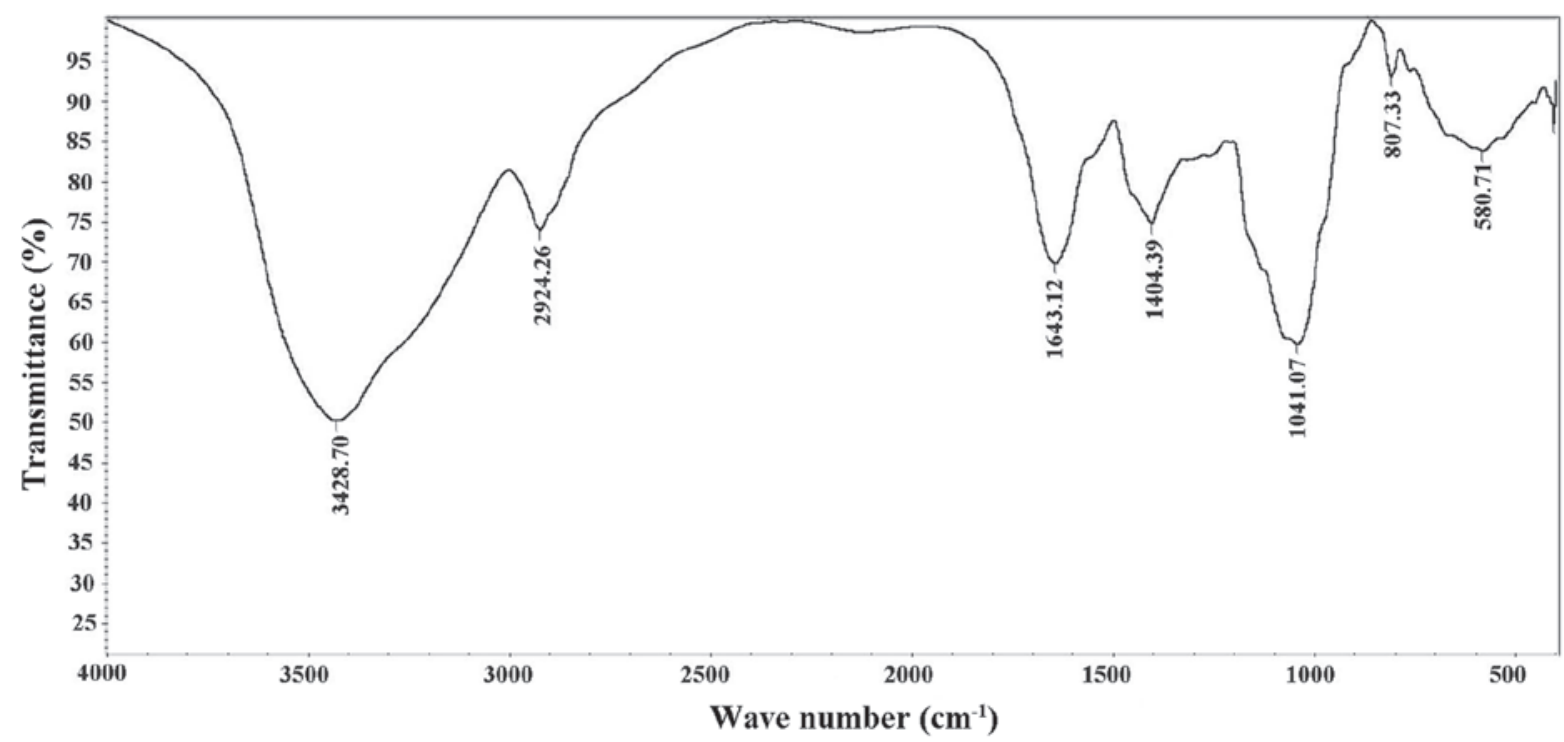

Figure 3. FTIR spectra of Cantharellus cibarius Fr. polysaccharide (CC-1). The horizontal coordinate represents the wave number, and the longitudinal coordinate indicates the absorption peak.

of $800-300 \mathrm{~cm}^{-1}$ correspond to $\mathrm{C}=\mathrm{C}$ stretching and $\mathrm{C}-\mathrm{OH}$ bending modes. The bands at $580.71 \mathrm{~cm}^{-1}$ were due to $\mathrm{C}-\mathrm{H}$ rocking vibration.

Analysis of the nuclear magnetic resonance (NMR) experiment results. The hydrogen spectrum of CC-1 is shown in Fig. 4. In the ${ }^{1} \mathrm{H}$ NMR(400HZ) spectrum, $\delta 4.99$ and $\delta 4.96$ indicate there were two anomeric hydrogen existing in CC-1, suggesting that $\mathrm{CC}-1$ was composed of two monosaccharides. $\delta 4.79$ was the hydrogen signal of water. The signals at $\delta 3.27-\delta 4.49$ are the signal peak of remaining proton which mostly formed by a number of signal peaks overlapping. The ${ }^{13} \mathrm{C}-\mathrm{NMR}$ spectrum of CC-1 (Fig. 5) showed the anomeric peaks were centralised in $\delta$ 99.38- $\delta 102.92 \mathrm{ppm}$, indicating there was $\alpha$ anomeric configuration of monomer in CC-1. The presence of CC-1 signal confirmed that all monomers should be pyran ring, as furan ring signals should be around $\delta 107-109 \mathrm{ppm}$. According to the literature, the resonance in the region of 98-102 ppm in the ${ }^{13} \mathrm{C}$ NMR $(400 \mathrm{MHz})$ spectrum of CC-1 was attributed to the anomeric carbon atoms of $\beta$-D-glucose and $\alpha$-D-xylopyranose. The assignment of the carbon atom signals is shown in Table I.

Monosaccharide composition analysis. The composition analysis of polysaccharides is an important step to control the quality and to obtain basic information on the 


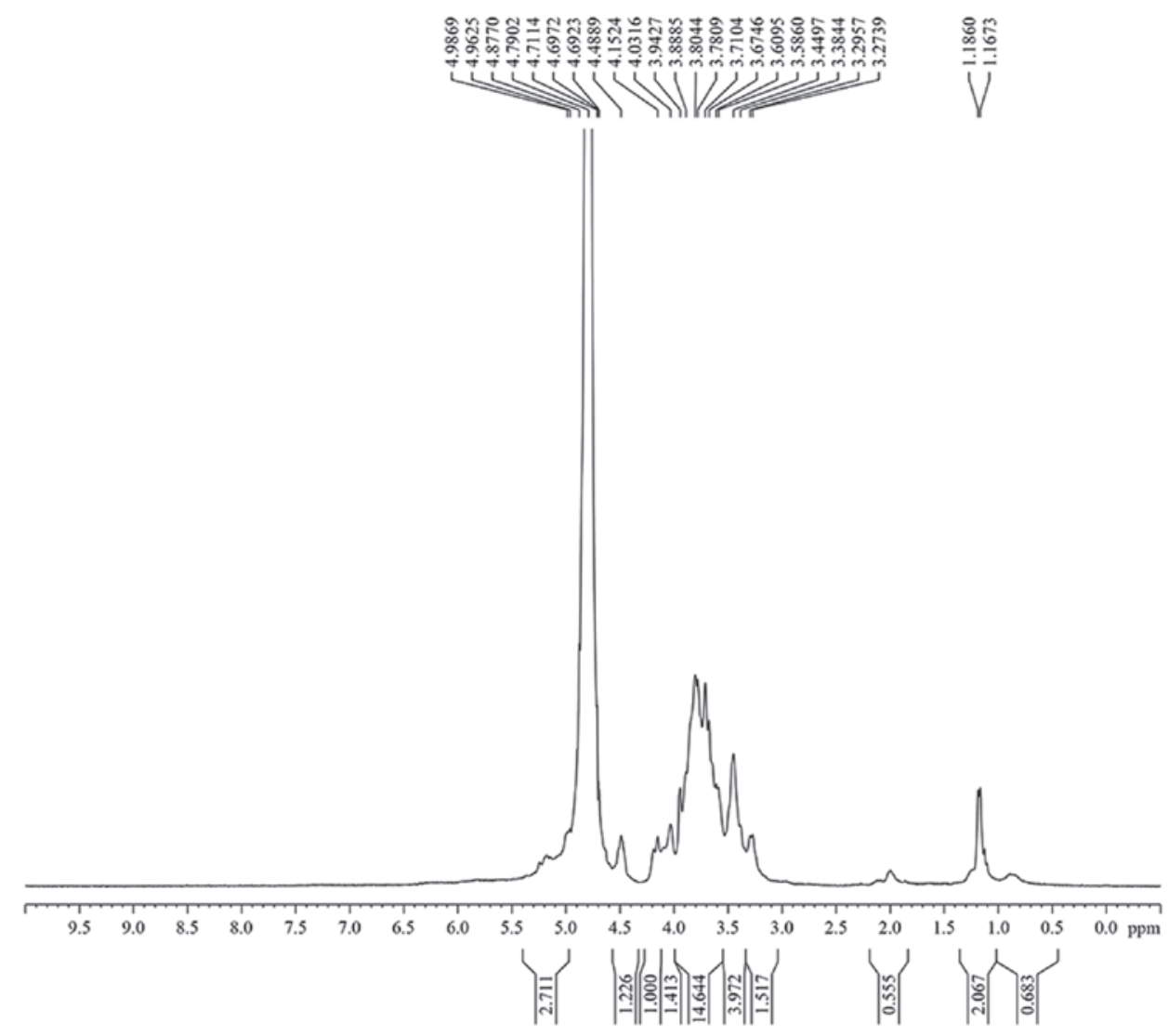

Figure 4. The ${ }^{1} \mathrm{H}$ nuclear magnetic resonance (NMR) spectra of Cantharellus cibarius Fr. polysaccharide (CC-1). The horizontal coordinate represents the value of chemical shift.
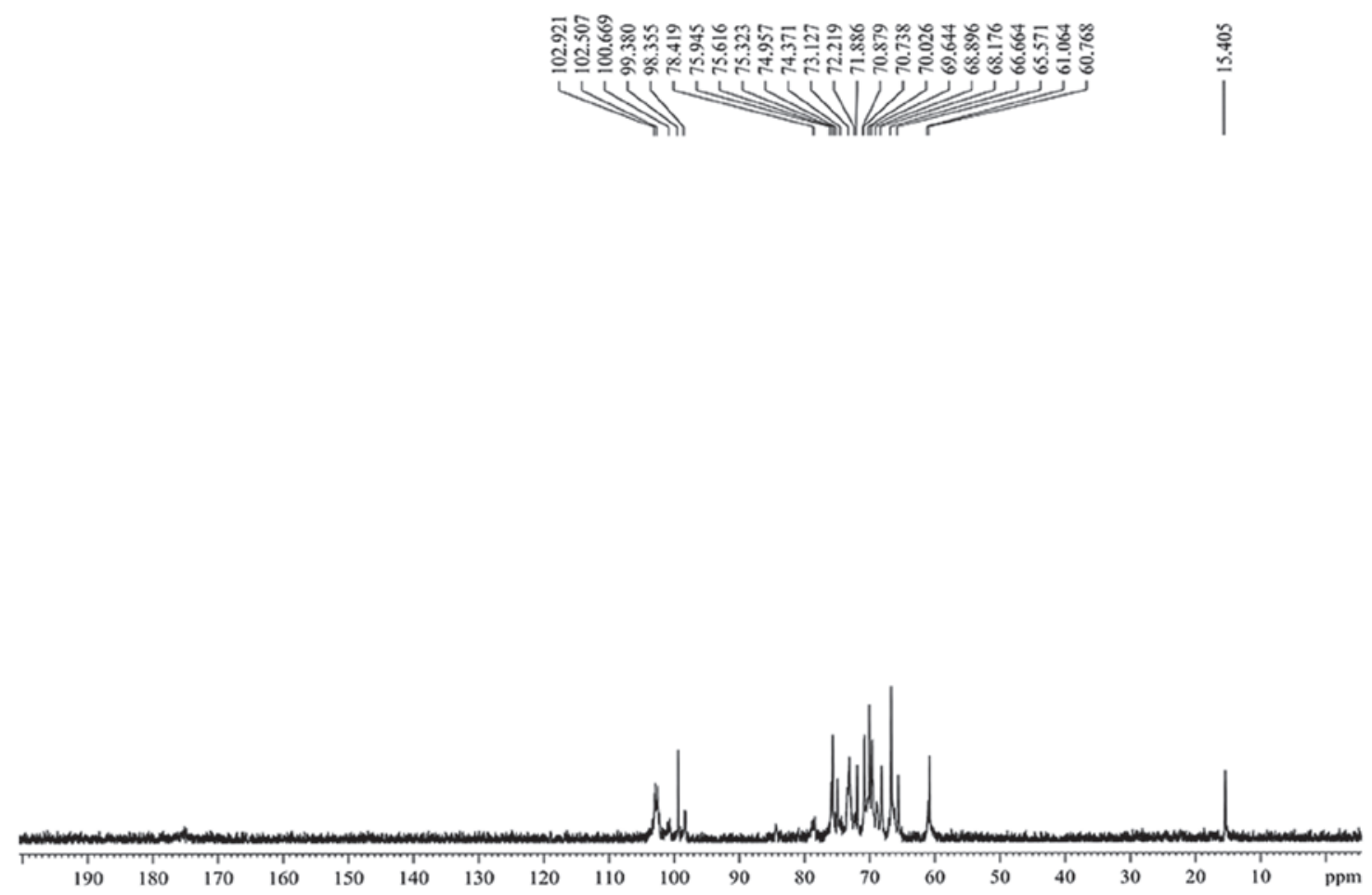

Figure 5. The ${ }^{13} \mathrm{C}$ nuclear magnetic resonance (NMR) spectra of Cantharellus cibarius Fr. polysaccharide (CC-1). The horizontal coordinate represents the value of chemical shift.

polysaccharides. In this study, the CC-1 polysaccharide samples were hydrolyzed with TFA and then the component monosaccharides were analyzed by HPLC with Agilent refractive index detector (Fig. 6). Compared with the retention time 


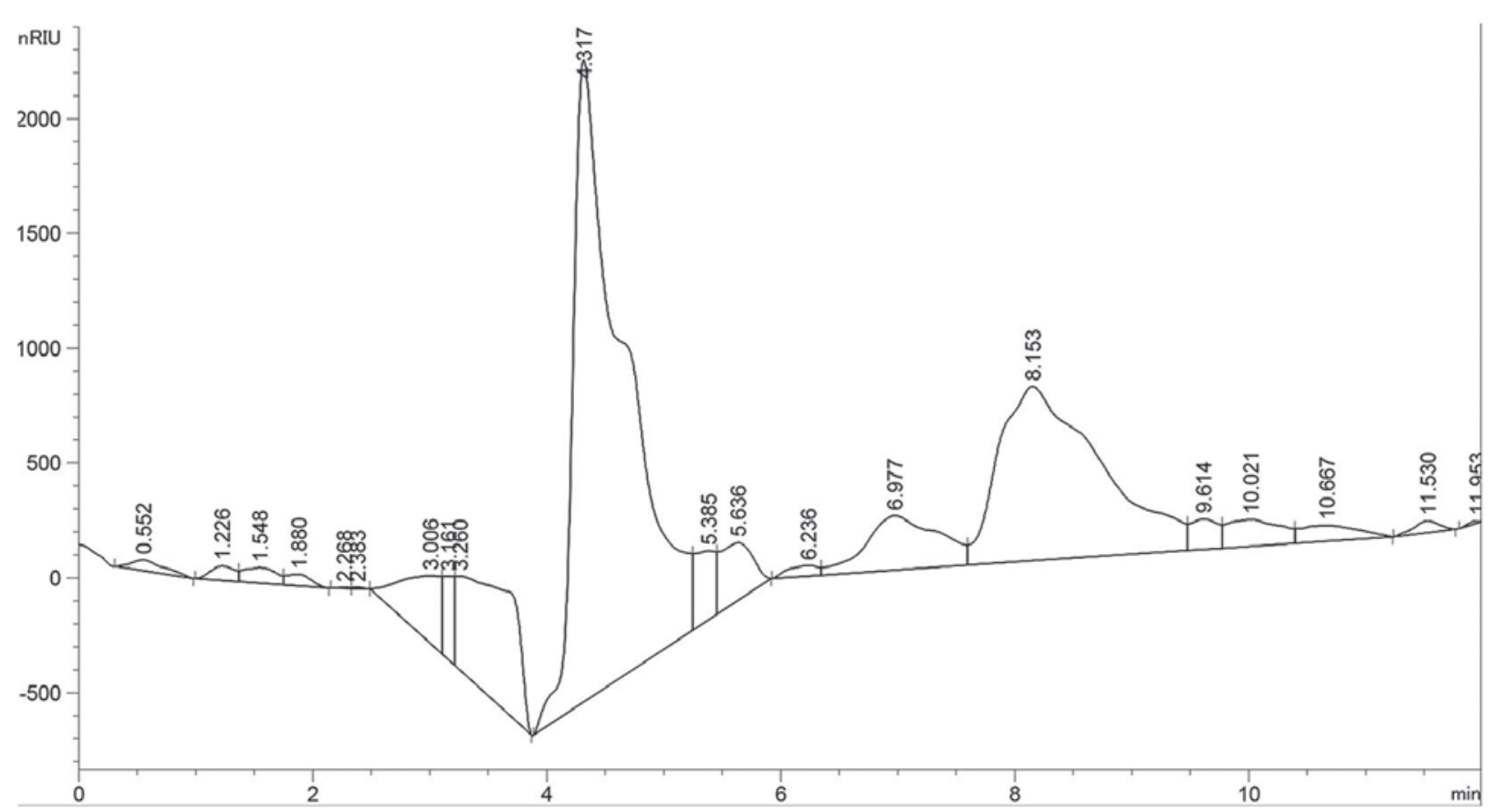

Figure 6. The component monosaccharides analysis of Cantharellus cibarius Fr. polysaccharide (CC-1) by high performance liquid chromatography (HPLC). Compared with the retention time of the standard monosaccharide, the peak at retention time of 8.135 min represents the $\beta$-D-glucose and the peak at retention time of $6.977 \mathrm{~min}$ represents the $\alpha$-D-xylopyranose, which ratios were 5:1.

Table II. GC-MS results of methylation analysis of CC-1.

\begin{tabular}{lcc}
\hline Methylated sugar & Linkage & $\mathrm{m} / \mathrm{z}$ \\
\hline $2,3,6-\mathrm{Me}-4$-Glu & $4-$ & $15,41,45,59,73,88,101,116,133,146,159,174,187,207,229$ \\
$2,3-\mathrm{Me}-1,4,6$-Glu & $1,4,6-$ & $59,73,89,103,117,133,147,159,175,191,205,217,232,243,259,287,377$ \\
$2,3,6-\mathrm{Me}-1,4-\mathrm{Glu}$ & $1,4-$ & $29,45,59,73,88,101,113,133,146,159,175,185,201,217,232$ \\
$2,3,4-\mathrm{Me}-1$-Xyl & $1-$ & $15,41,45,58,73,88,101,115,133,149,159,174,185$ \\
\hline
\end{tabular}

CC-1, Cantharellus cibarius Fr. polysaccharide; GC-MS, gas chromatography-mass spectrometry.

Table I. ${ }^{13} \mathrm{C}$ chemical shift data $(\delta, \mathrm{ppm})$ for polysaccharide CC-1.

\begin{tabular}{|c|c|c|c|c|c|c|}
\hline \multirow[b]{2}{*}{ Sugar residues } & \multicolumn{6}{|c|}{ Chemical shift, $\delta(\mathrm{ppm})$} \\
\hline & $\mathrm{C} 1$ & $\mathrm{C} 2$ & $\mathrm{C} 3$ & $\mathrm{C} 4$ & $\mathrm{C} 5$ & C6 \\
\hline$\rightarrow 4)-\alpha-D-G l c p-(1 \rightarrow$ & 98.36 & 66.66 & 70.88 & 73.13 & 68.90 & 65.57 \\
\hline$\rightarrow 3,6)-\alpha-D-G l c p-(1 \rightarrow$ & 99.38 & 68.18 & 71.89 & 74.96 & 69.90 & 70.03 \\
\hline$\alpha$-D-lyx- $(1 \rightarrow$ & 102.51 & 69.64 & 72.22 & 78.42 & 70.76 & 61.06 \\
\hline
\end{tabular}

NMR, nuclear magnetic resonance; CC-1, Cantharellus cibarius Fr. polysaccharide.

of the standard monosaccharide, the peak at retention time of 8.135 min represents the $\beta$-D-glucose and the peak at retention time of $6.977 \mathrm{~min}$ represents the $\alpha-\mathrm{D}$-xylopyranose, at ratio of 5:1. The chromatogram using an HPLC-RID method shows that $\mathrm{CC}-1$ was composed of two monosaccharides, $\beta$-D-glucose and $\alpha$-D-xylopyranose, which was in good agreement with the D-configuration monosaccharide according to GC-MS analysis.

Methylation analysis. The methylated products of CC-1 were hydrolysed with acid, converted into alditol acetate and analysis by GC-MS. The experimental data are listed in Table II. The information in MS showed that fragment ion peaks were consistent with data of D-configuration monosaccharide fragment ion peaks and it can be concluded that the xylose and glucose residues were D-configurations, respectively. The GC-MS spectrum (Fig. 7), results of the silane experiments need to be discussed further because of the incomplete methylation, so after the comprehensive analysis of the data, we inferred that the design feature of the CC-1 may be as follows: the branched residue was $(1 \rightarrow 4)$-linked-D-glucosepyranose and $(4 \rightarrow 6)$-linked-Dxylopyranose revealing that $(1 \rightarrow 4)$-linked-D-glucosepyranose possible form the backbone structure. Residues of branch structure were terminated with $\alpha$-D-xylopyranose resides. It is concluded that a repeating unit of $\mathrm{CC}-1$ has a backbone of 1,4-linked- $\beta$-D-glucose which branched at O-6 and the 

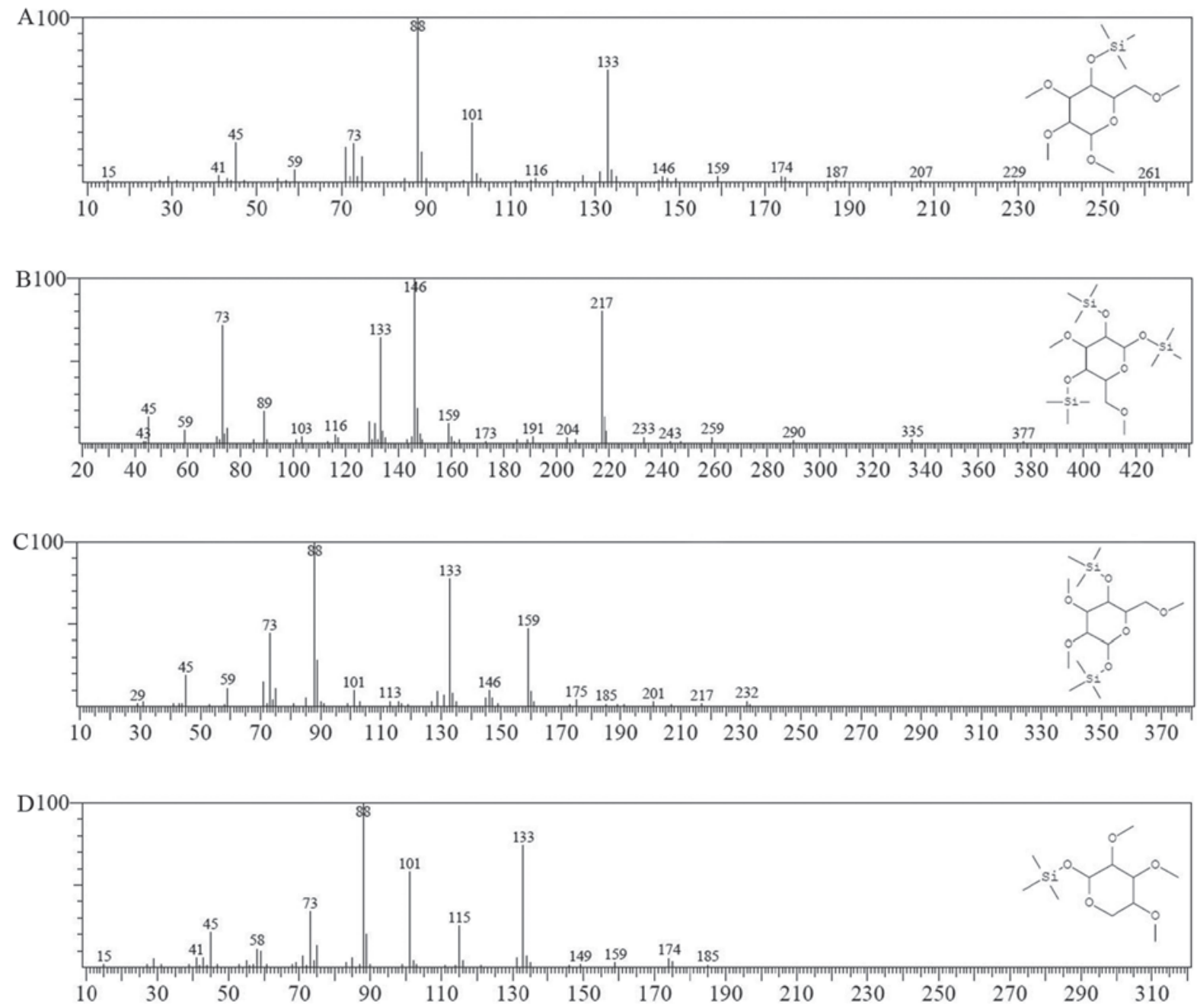

Figure 7. GC-MS chromatogram of Cantharellus cibarius Fr. polysaccharide (CC-1). The horizontal coordinate represents the retention time. (A) The fragment ion peaks of 2,3,6-Me 4-Glu; (B) the fragment ion peaks of 2,3-Me 1,4,6-Glu; (C) the fragment ion peaks of 2,3,6-Me 1,4-Glu; (D) the fragment ion peaks of 2,3,4-Me 1-Xyl.

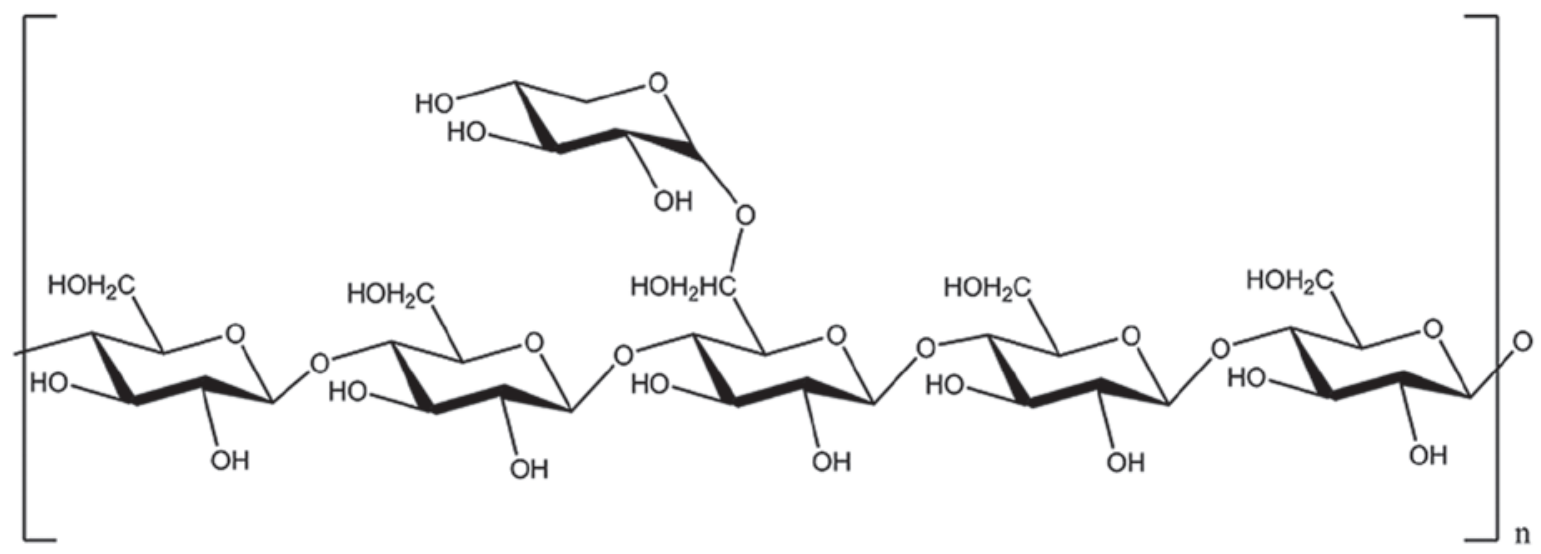

Figure 8. Predicted chemical structure of Cantharellus cibarius Fr. polysaccharide (CC-1). The structure of CC-1 had a backbone of 1,4-linked- $\beta$-D-glucose which branched at O-6 and the branches were mainly composed of a $\rightarrow 1)-\alpha$-D-xylopyranose residue.

branches were mainly composed of a $\rightarrow 1)-\alpha$-D-xylopyranose residue (Fig. 8).

$D P P H^{-}$free radical scavenging activity of $C C-1$. The decrease of the absorbance of the resultant solution is caused by the removal of the DPPH free radical. Obviously, the color changed from purple to yellow. CC-1 exhibited an antioxidant activity compared with that of standard ascorbic acid at varying concentration tested. There was a dose-dependent increase in the percentage of antioxidant activity for all concentrations 


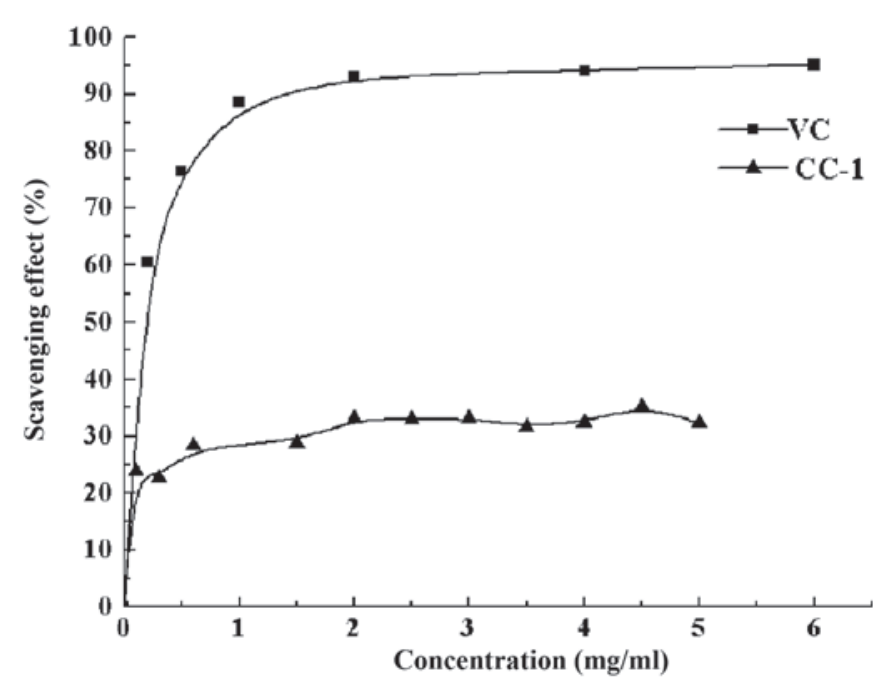

Figure 9. DPPH` radical scavenging effect of Cantharellus cibarius Fr. polysaccharide (CC-1). The horizontal coordinate indicates the concentration and the vertical coordinate indicates the scavenging effect (100\%).

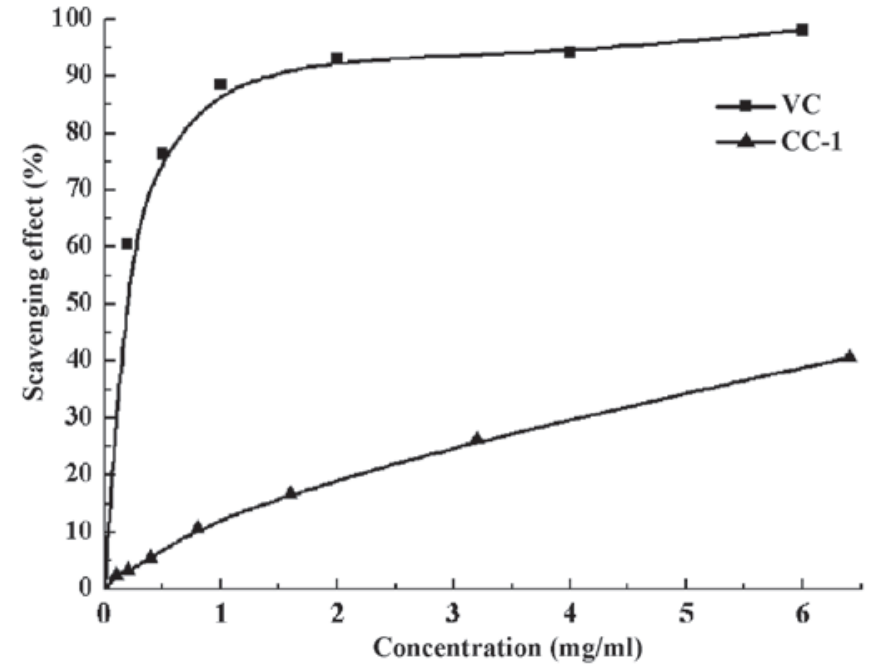

Figure 10. ABTS ${ }^{+}$radical scavenging activity of Cantharellus cibarius Fr. polysaccharide (CC-1). The horizontal coordinate indicates the concentration and the vertical coordinate indicates the scavenging effect (100\%).
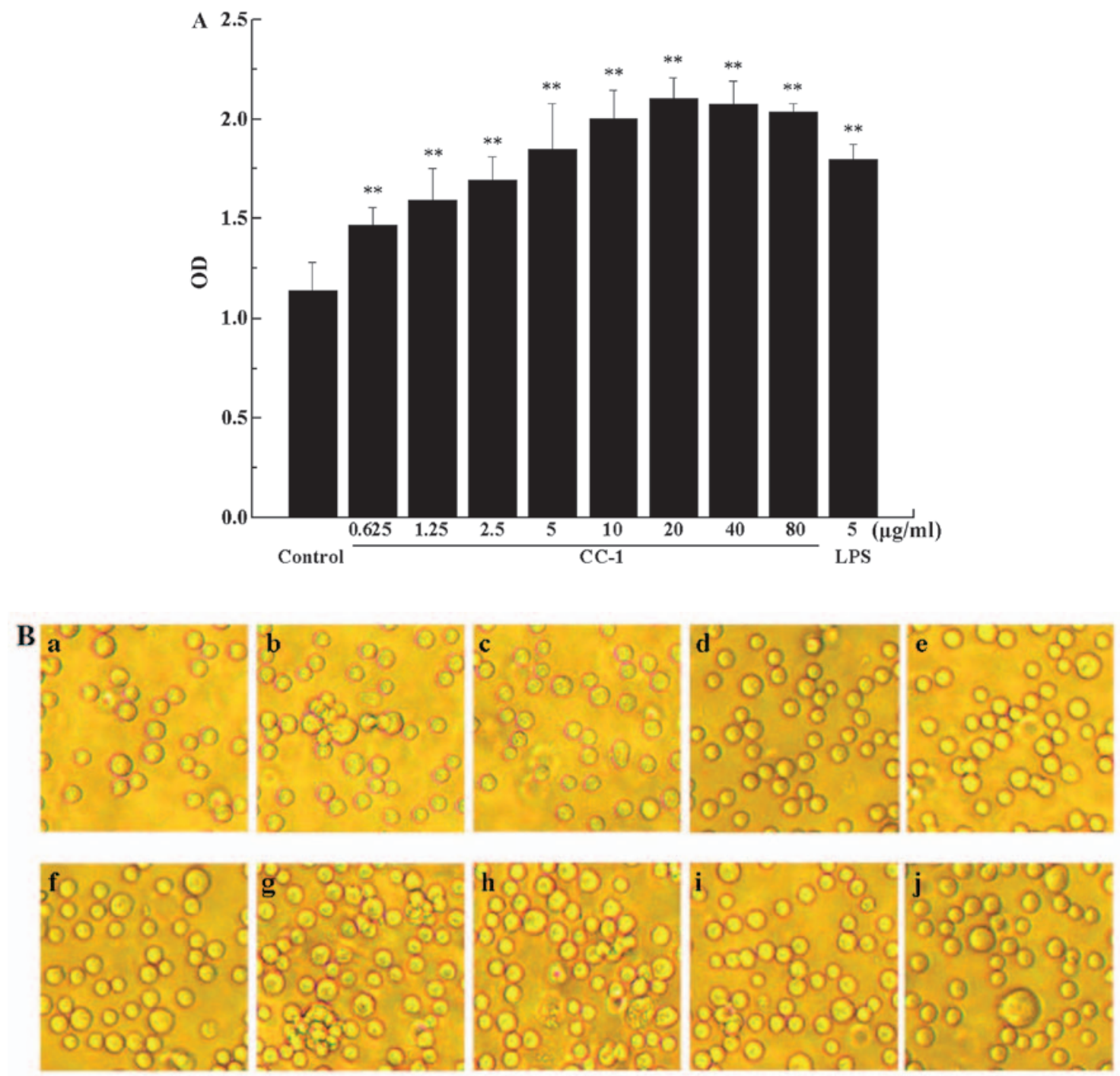

Figure 11. (A) The effect of Cantharellus cibarius Fr. polysaccharide (CC-1) on the proliferation of B cells. The horizontal coordinate indicates the concentration of CC-1 and the vertical coordinate indicates the OD value of the B cells. (B) The cell morphology effect of CC-1 on the proliferation of B cells. When the concentration of $20 \mu \mathrm{g} / \mathrm{ml}$ of CC-1 was used to stimulate the B cell, the B cell clusters up most obviously. a, the blank group; b-i, the CC-1 experimental groups, cells treated with $0.625,1.25,2.5,5,10,20,40$ and $80 \mu \mathrm{g} / \mathrm{ml} \mathrm{CC-1;} \mathrm{j,} \mathrm{the} \mathrm{lipopolysaccharide} \mathrm{(LPS)} \mathrm{group}(5 \mu \mathrm{g} / \mathrm{ml})$. Control, the blank group. Each value is presented as the mean $\pm \mathrm{SD}(\mathrm{n}=5)$. ${ }^{*} \mathrm{P}<0.05$ and ${ }^{* *} \mathrm{P}<0.01$ compared with the control group. 

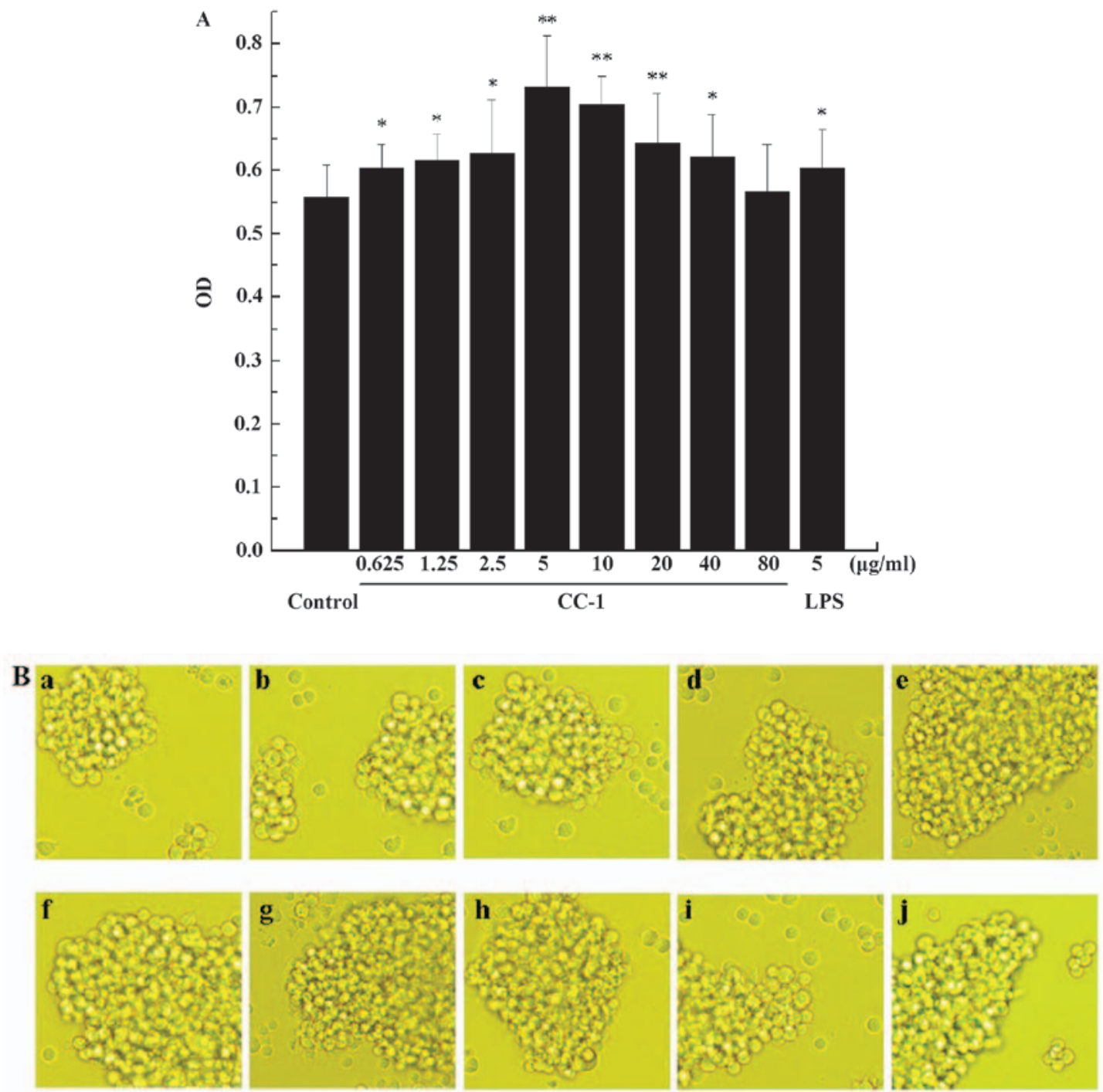

Figure 12. (A) The effect of Cantharellus cibarius Fr. polysaccharide (CC-1) on the proliferation of T cells. The horizontal coordinate indicates the concentration of CC-1 and the vertical coordinate indicates the OD value of the T cells. (B) The cell morphology effect of CC-1 on the proliferation of T cells. When the concentration of $5 \mu \mathrm{g} / \mathrm{ml}$ of CC-1 wasused to stimulate the T cell, the T cell has the most vigorous proliferative capacity. a, the blank group; b-i, the CC-1 experiment groups, cells treated with $0.625,1.25,2.5,5,10,20,40$ and $80 \mu \mathrm{g} / \mathrm{ml} \mathrm{CC}-1 ; \mathrm{j}$, the lipopolysaccharide (LPS) group (5 $\mu \mathrm{g} / \mathrm{ml})$. Control, the blank group. Each value is presented as the mean $\pm \mathrm{SD}(\mathrm{n}=5) .{ }^{*} \mathrm{P}<0.05$ and ${ }^{* * *} \mathrm{P}<0.01$ compared with the control group.

tested (Fig. 9). The CC-1 at a concentration of $0.1 \mathrm{mg} / \mathrm{ml}$ showed a percentage inhibition of $23.81 \%$ and for $4.5 \mathrm{mg} / \mathrm{ml}$ it achieved maximum of $35.23 \%$. The clearance rate stabilized at around $23-36 \%$ when the concentration of CC-1 is in the range of $0.1-5 \mathrm{mg} / \mathrm{ml}$ without significant change. However, the scavenging ability was lower than that of Vc.

$A B T S^{+}$radical scavenging activity of $C C-1$. $\mathrm{ABTS}^{+}$is used to mensurate total antioxidant capacity. $\mathrm{ABTS}^{+}$will change into green under the appropriate oxidation, and the oxidation will be suppressed in the presence of antioxidants. The $\mathrm{ABTS}^{+}$ radical scavenging activity of CC-1 was tested spectrophotometrically at $734 \mathrm{~nm}$. The results of antioxidant activity of CC-1 was expressed as shown in Fig. 10. The scavenging ability on $\mathrm{ABTS}^{+}$radical of $\mathrm{CC}-1$ is positively correlated when its concentration is $0.1-6.4 \mathrm{mg} / \mathrm{ml}$. When the concentration of CC-1 is $6.4 \mathrm{mg} / \mathrm{ml}$, the scavenging rate of $\mathrm{ABTS}^{+}$ free radical can reach $40.70 \%$, and the $\mathrm{IC}_{50}$ value of $\mathrm{CC}-1$ was $7.8624 \mathrm{mg} / \mathrm{ml}$.
Effect of CC-1 on B cell activation in vitro. B cells, also known as B lymphocytes, are a subtype of white blood cells of the lymphocytes. They function in the humoral immunity component of the adaptive immune system by secreting antibodies. The stimulation of CC-1 on B cells is shown in Fig. 11A. Cell proliferation activity was very low when $\mathrm{B}$ cells were exposed to medium alone, whereas incubation of these cells with increasing concentrations of CC-1 was associated with a dose-dependent increase in cell proliferation activity. Compared with the control group, the low concentration of CC-1 significantly promoted B cells proliferation $(0.625-80 \mu \mathrm{g} / \mathrm{ml}, \mathrm{p}<0.01)$. Furthermore, cell proliferation activity at $5 \mu \mathrm{g} / \mathrm{ml}$ concentrations of CC-1 were comparable to or even greater than that elicited by $5 \mu \mathrm{g} / \mathrm{ml}$ LPS. It is worth noting that, the optimal concentration of CC-1 is $20 \mu \mathrm{g} / \mathrm{ml}$, when more than this concentration, the cell growth rate decline, but it is still very significant.

Effect of CC-1 on T cell activation in vitro. T cells are a type of lymphocytes which play a central role in cell-mediated 
immunity. They are called $\mathrm{T}$ cells because they mature in the thymus from thymocytes. The stimulation of CC- 1 on $\mathrm{T}$ cells are shown in Fig. 12A. Compared with the control group, the low concentration of CC-1 significantly promote $\mathrm{T}$ cell proliferation $(0.625-2.5 \mu \mathrm{g} / \mathrm{ml}, \mathrm{p}<0.05 ; 5-20 \mu \mathrm{g} / \mathrm{ml}, \mathrm{p}<0.01)$. Cell proliferation activity at $5 \mu \mathrm{g} / \mathrm{ml}$ concentration of CC-1 was comparable to or even greater than that elicited by $5 \mu \mathrm{g} / \mathrm{ml} \mathrm{LPS}$, and the proliferation effect of $\mathrm{T}$ cells reached the maximum value. When the concentration was further increased, the rate of the increase in $\mathrm{T}$ cells declined.

Cell morphology observation. The cell morphology of B cells and T cells is revealed in Figs. 11B and 12B, respectively. With the increase of the concentration of CC-1, the cells accelerated division and became larger and larger. When the concentration of $20 \mu \mathrm{g} / \mathrm{ml}$ of CC-1 was used to stimulate the B cell, the $\mathrm{B}$ cells clustered up most obviously. When the concentration of $5 \mu \mathrm{g} / \mathrm{ml}$ of CC-1 was used to stimulate the T cells, the T cells showed the most vigorous proliferative capacity.

Conclusions and discussion. Villares et al (33) previously reported the structural characterization of two polysaccharides isolated from the fruiting bodies of the wild edible mushroom Cantharellus cibarius. The polysaccharide from the boiling water fraction (PsCcib-I) was a glucan-type carbohydrate with a molecular weight of 15,002 kDa. The methylation analysis and NMR experiments showed that PsCcib-I was composed of a main chain consisting of $\alpha-(1 \rightarrow 6)-$ Glc units with $\beta$ - $(1 \rightarrow 4)$-linked branches every third glucose residue. The present study revealed that the polysaccharide obtained from Cantharellus cibarius Fr., is a heteropolysaccharide, namely $\mathrm{CC}-1$. The purified polysaccharide (CC-1) prepared was confirmed of high purity. Structure analysis indicated CC-1 consists of a backbone of 1,4-linked- $\beta$ D-glucose which branched at O-6 and the branches were mainly composed of $\mathrm{a} \rightarrow 1$ )- $\alpha$-D-xylopyranose residue.

In addition, in the experiments of DPPH free radical scavenging activity, under the same experimental condition, the scavenging ability of CC-1 was lower than that of Vc. DPPH is a stable nitrogen centered free radical and its stability is from the three benzene ring resonance stabilization, and steric hindrance, cliping on the nitrogen atom of the intermediate unpaired electrons, thus cannot function as electron pairs. As a stable free radical, DPPH can capture other free radicals. According to the respective structure characteristics of the polysaccharide molecules, we can infer that the average molecular weight and the degree of polymerization of polysaccharide extracted are greater, while the amount of isolated hydroxyl are less. Therefore, the scavenging activity of CC-1 through the direct reduction of the electron and proton depend on the isolated hydroxyl, which make it possible to decease the capacity of the $\mathrm{N}=\mathrm{N}$ double bond in DPPH by oxidationreduction reaction. This may be the cause of DPPH free radical scavenging rate being lower than the rate of the $\mathrm{ABTS}^{+}$free radical scavenging under the action of CC-1.

$\mathrm{T}$ lymphocytes, referred to as $\mathrm{T}$ cells, originate from bone marrow, migrate to the thymus for differentiation and mature. Mature T cells can specifically bind with target cells, directly kill the target cells, or release the lymphatic factors, which enhances the immune effect mainly in the body's cellular immunity. B cells are from the auxe of hematopoietic stem cells of mammalian bone marrow or bird bursa. In antigen stimulation, B cells differentiate into plasma cells that synthesize and secrete antibodies, and perform humoral immune function. In this study, CC-1 could effect the proliferation and cell morphology of T and B cells. The LPS as the positive control. The results show that, $\mathrm{T}$ and $\mathrm{B}$ cells can promote proliferation effect and CC-1 concentration $(<5 \mu \mathrm{g} / \mathrm{ml})$ was positively related and cell morphology was not changed, with good state of cells. Polysaccharides with high molecular weight in different concentrations will lead to different aggregation degrees of molecules, which will eventually affect the immune activity in B cells and $\mathrm{T}$ cells in different concentrations of CC-1 since B cells and T cells have different receptors on the surface. But the specific molecular mechanism needs further study. Cantharellus cibarius Fr. may be used in nutritional or pharmaceutical fields.

\section{Acknowledgements}

The authors would like to thank all the participants, who provided feedback so hat the research on the programme could be achieved.

\section{Funding}

This study was supported by the National Natural Science Foundation of China (31400016 and 31200012), the Cultivate Major Projects of Sichuan Province (16CZ0018), the Nanchong Science and Technology Bureau of Sichuan Province (16YFZJ0043), the Talent Program of China West Normal University (17YC328, 17YC136 and 17YC329), the National Training Project of China West Normal University (17c039) and the Innovative Team Project of China West Normal University (CXTD 2017-3).

\section{Availability of data and material}

The data supporting the findings can be found in the Key Laboratory of Southwest China Wildlife Resources Conservation, College of Life Sciences, China West Normal University, Nanchong, China.

\section{Authors' contributions}

YH conceived the presented idea. DZ and XD carried out the experiment. DZ and YH wrote the manuscript. All authors discussed the results and implications and commented on the manuscript at all stages.

\section{Ethics approval and consent to participate}

Not applicable.

\section{Consent for publication}

Not applicable.

\section{Competing interests}

The authors declare that they have no competing interests. 


\section{References}

1. Brown MW, Kolisko M, Silberman JD and Roger AJ: Aggregative multicellularity evolved independently in the eukaryotic supergroup Rhizaria. Curr Biol 22: 1123-1127, 2012.

2. Pawlowski J, Audic S, Adl S, Bass D, Belbahri L, Berney C, Bowser SS, Cepicka I, Decelle J, Dunthorn M, et al; CBOL Protist Working Group: CBOL protist working group: Barcoding eukaryotic richness beyond the animal, plant, and fungal kingdoms. PLoS Biol 10: e1001419, 2012.

3. Mansour-Benamar M, Savoie JM and Chavant L: Valorization of solid olive mill wastes by cultivation of a local strain of edible mushrooms. C R Biol 336: 407-415, 2013.

4. Chang ST: The World Mushroom Industry: Trends and technological development. Int J Med Mushrooms 8: 297-314, 2006.

5. Pacheco L: Sex differences in mushroom gathering: Men expend more energy to obtain equivalent benefits. Evol Hum Behav 31: 289-297, 2010.

6. Leonti M: The future is written: Impact of scripts on the cognition, selection, knowledge and transmission of medicinal plant use and its implications for ethnobotany and ethnopharmacology. J Ethnopharmacol 134: 542-555, 2011.

7. Hussain H, Krohn K, Schulz B, Draeger S, Nazir M and Saleem M: Two new antimicrobial metabolites from the endophytic fungus, Seimatosporium sp. Nat Prod Commun 7: 293-294, 2012.

8. Yang WT, Shi SH, Jiang YL, Zhao L, Chen HL, Huang KY, Yang GL and Wang CF: Genetic characterization of a densovirus isolated from great tit (Parus major) in China. Infect Genet Evol 41: 107-112, 2016.

9. Kievit FM, Florczyk SJ, Leung MC, Wang K, Wu JD, Silber JR, Ellenbogen RG, Lee JS and Zhang M: Proliferation and enrichment of CD133(+) glioblastoma cancer stem cells on 3D chitosan-alginate scaffolds. Biomaterials 35: 9137-9143, 2014.

10. Obach RS: Pharmacologically active drug metabolites: Impact on drug discovery and pharmacotherapy. Pharmacol Rev 65: 578-640, 2013.

11. Guo H, Yi W, Song JK and Wang PG: Current understanding on biosynthesis of microbial polysaccharides. Curr Top Med Chem 8: 141-151, 2008.

12. Ferreira SS, Passos CP, Madureira P, Vilanova M and Coimbra MA: Corrigendum to 'Structure-function relationships of immunostimulatory polysaccharides: A review' [Carbohydr. Polym. 132 (2015) 378-396]. Carbohydr Polym 147: 557-558, 2016.

13. Yeung MK: Molecular and genetic analyses of Actinomyces spp. Crit Rev Oral Biol Med 10: 120-138, 1999.

14. Ganeshapillai J, Vinogradov E, Rousseau J, Weese JS and Monteiro MA: Clostridium difficile cell-surface polysaccharides composed of pentaglycosyl and hexaglycosyl phosphate repeating units. Carbohydr Res 343: 703-710, 2008.

15. Ebert B, Rautengarten C, Guo X, Xiong G, Stonebloom S, Smith-Moritz AM, Herter T, Chan LJ, Adams PD, Petzold CJ, et al: Identification and characterization of a golgi-localized UDP-xylose transporter family from arabidopsis. Plant Cell 27: $1218-1227,2015$

16. Hadley B, Maggioni A, Ashikov A, Day CJ, Haselhorst T and Tiralongo J: Structure and function of nucleotide sugar transporters: Current progress. Comput Struct Biotechnol J 10: 23-32, 2014.

17. Dubois M, Gibbs KA, Hamilton JK, Rebers PA and Smith F: Colorimetric methods for the determination of sugars and related substances. Anal Chem 28: 350-356, 1956.

18. Wang F, Hou Y, Ding X, Hou W, Song B, Wang T, Li J and Zeng Y: Structure elucidation and antioxidant effect of a polysaccharide from Lactarius camphoratum (Bull.) Fr. Int J Biol Macromol 62: 131-136, 2013.
19. Kim YT, Kim EH, Cheong C, Williams DL, Kim CW and Lim ST: Structural characterization of beta-D- $(1 \rightarrow 3,1 \rightarrow 6)$-linked glucans using NMR spectroscopy. Carbohydr Res 328: 331-341, 2000.

20. Cao W, Li XQ, Liu L, Wang M, Fan HT, Li C, Lv Z, Wang X and Mei Q: Structural analysis of water-soluble glucans from the root of Angelica sinensis (Oliv.) Diels. Carbohydr Res 341: 1870-1877, 2006.

21. Wang Z, Luo D and Liang Z: Structure of polysaccharides from the fruiting body of Hericium erinaceus Pers. Carbohydr Polym 57: 241-247, 2004

22. Ding X, Hou Y, Hou W, Zhu Y, Fu L and Zhu H: Structure elucidation and anti-tumor activities of water-soluble oligosaccharides from Lactarius deliciosus (L. ex Fr.) Gray. Pharmacogn Mag 11: 716-723, 2015.

23. Ding X, Hou Y, Zhu Y, Wang P, Fu L, Zhu H, Zhang N, Qin H, Qu W, Wang F, et al: Structure elucidation, anticancer and antioxidant activities of a novel polysaccharide from Gomphus clavatus Gray. Oncol Rep 33: 3162-3170, 2015.

24. Gentili A, Caretti F, D'Ascenzo G, Marchese S, Perret D, Di Corcia D and Rocca LM: Simultaneous determination of water-soluble vitamins in selected food matrices by liquid chromatography/electrospray ionization tandem mass spectrometry. Rapid Commun Mass Spectrom 22: 2029-2043, 2008.

25. Luo A and Fan Y: In vitro antioxidant of a water-soluble polysaccharide from Dendrobium fimhriatum Hook.var.oculatum Hook. Int J Mol Sci 12: 4068-4079, 2011.

26. Auddy B, Ferreira M, Blasina F, Lafon L, Arredondo F, Dajas F, Tripathi PC, Seal T and Mukherjee B: Screening of antioxidant activity of three Indian medicinal plants, traditionally used for the management of neurodegenerative diseases. J Ethnopharmacol 84: 131-138, 2003.

27. Sudo A, Uenishi K and Endo T: Anionic copolymerization of epoxide with bifunctional aromatic lactone derived from 2-methylresorcinol. J Polym Sci Pol Chem 46: 3447-3451, 2008.

28. Bradford PA, Petersen PJ, Young M, Jones CH, Tischler M and O'Connell J: Tigecycline MIC testing by broth dilution requires use of fresh medium or addition of the biocatalytic oxygen-reducing reagent oxyrase to standardize the test method. Antimicrob Agents Chemother 49: 3903-3909, 2005.

29. Ding X, Hou Y and Hou W: Structure feature and antitumor activity of a novel polysaccharide isolated from Lactarius deliciosus Gray. Carbohydr Polym 89: 397-402, 2012.

30. Hou Y, Ding X and Hou W: Composition and antioxidant activity of water-soluble oligosaccharides from Hericium erinaceus. Mol Med Rep 11: 3794-3799, 2015.

31. Luo D: Identification of structure and antioxidant activity of a fraction of polysaccharide purified from Dioscorea nipponica. Makino. Carbohydr Polym 71: 544-549, 2008.

32. Hou Y, Ding X, Hou W, Song B, Wang T, Wang F, Li J, Zeng Y, Zhong J, Xu T, et al: Pharmacological evaluation for anticancer and immune activities of a novel polysaccharide isolated from Boletus speciosus Frost. Mol Med Rep 9: 1337-1344, 2014.

33. Villares A, García-Lafuente A, Guillamón E and MateoVivaracho L: Separation and characterization of the structural features of macromolecular carbohydrates from wild edible mushrooms. Bioac Carbohyd Diet Fibr 2: 15-21, 2013.

This work is licensed under a Creative Commons Attribution-NonCommercial-NoDerivatives 4.0 International (CC BY-NC-ND 4.0) License. 